\title{
Molecular Therapeutics of Non-Small Cell Lung Cancer (NSCLC) and Challenges in Repeat Tissue Biopsy
}

\author{
Devanna Vasista Ganesha1, Radheshyam Naik², Suhail Sayeed Mufti ${ }^{3}$, Hrishi Varayathu ${ }^{3 *}$ \\ ${ }^{1}$ Department of Medical Oncology, Saint Johns Medical College Hospital, Bangalore, India \\ ${ }^{2}$ Department of Medical Oncology, Healthcare Global Enterprises Limited, Bangalore, India \\ ${ }^{3}$ Department of Translational Medicine and Therapeutics, Healthcare Global Enterprises Limited, Bangalore, India \\ Email: ^hrishivarayathu@gmail.com
}

How to cite this paper: Ganesha, D.V., Naik, R., Mufti, S.S. and Varayathu, H. (2021) Molecular Therapeutics of Non-Small Cell Lung Cancer (NSCLC) and Challenges in Repeat Tissue Biopsy. Advances in Lung Cancer, 10, 21-39.

https://doi.org/10.4236/alc.2021.103003

Received: April 19, 2021

Accepted: August 1, 2021

Published: August 4, 2021

Copyright (c) 2021 by author(s) and Scientific Research Publishing Inc. This work is licensed under the Creative Commons Attribution International License (CC BY 4.0)

http://creativecommons.org/licenses/by/4.0/

\begin{abstract}
With advances in targeted and personalized treatment for lung cancer, molecular analysis of tumors is routinely performed for sequencing of treatment options in patients with advanced non-small-cell lung cancer (NSCLC). Oncogene addiction due to driver mutations includes EGFR exon 20 insertion mutations, MET amplification, EML4-AL, KRAS G12C point mutations, RET rearrangements, HER2 amplification and mutations, and FGFR amplification and translocations. A re-biopsy at the time of tumor recurrence or progression after first-line treatment failure is important for further molecular assessment and personalized therapy. However, repeat tumor biopsies are fraught with challenges including access to the tumor, sample inadequacy, patient consent, patient performance status, safety, or physician's choice or assessment. Cytological specimens are gaining importance but are limited due to validation difficulties. Liquid biopsies, which are minimally invasive have shown promise to assess dynamic biomarkers using ctDNA analysis and are thus frequently considered in routine clinical practice in advanced NSCLC patients to guide further targeted treatment. Here we present a comprehensive review that emphasizes the significance of performing tumor re-biopsy in advanced stage NSCLC patients following resistance to first-line treatment and simultaneously highlights the current challenges in performing the same and the current status and future perspectives of liquid biopsy in NSCLC.
\end{abstract}

\section{Keywords}

Liquid Biopsy, Re-Biopsy, ctDNA, Driver Mutations 


\section{Introduction}

Globally, lung cancer has the highest mortality rate in men and the second highest in women [1]. Non-small cell lung cancer (NSCLC) is the most common type of lung cancer worldwide accounting for almost $85 \%$ of the cases [2]. The global incidence of epidermal growth factor receptor (EGFR) mutations in patients with NSCLC has been reported to be higher in the Asia-Pacific region (47\%) as compared to Europe (15\%) [3].

Beginning with gefitinib, a reversible EGFR small molecule tyrosine kinase inhibitor (TKIs), in the year 2003 [4] [5], a series of targeted treatments have been introduced in the last two decades for advanced-stage NSCLC having oncogenic mutations. Over these years, several small-molecule TKIs were approved for driver mutations like ALK, ROS1, BRAF, NTRK. Many of the TKIs are now used in first-line therapy, however, the development of resistance is a universal phenomenon with these which has led to the continuous development of further generations of compounds with higher potency and targeted towards the resistance mechanisms. Other less targetable oncogenic mutations seen in NSCLC include HER2, RET, KRAS, and MET.

The College of American Pathologists (CAP) Updated Molecular Testing Guideline for the Selection of Lung Cancer Patients for Treatment With Targeted Tyrosine Kinase Inhibitors, 2018, recommends molecular testing of NSCLC for BRAF, ERBB2 (Her2), KRAS, and MET along with the routine EGFR, ROS1, and ALK as part of larger testing panels [6].

This review aims to highlight the currently approved targeted therapies for advanced non-small cell lung cancer and describe the importance of re-biopsy in patients after first-line treatment failure, challenges associated with tissue re-biopsy, the role of cytopathology, and the implication of liquid biopsy as an alternative option for tissue re-biopsy.

\section{Methodology}

The review covered all countries with a web-based search of PubMed/Google Scholar published from 2009 to 2021. We used search terms such as 'rebiopsy and lung cancer', 'liquid biopsy and lung cancer' and 'repeated biopsy and lung cancer ${ }^{2}$ in our literature search. Publications in languages other than English and trials involving non-human subjects were excluded. Letter to the editor and case reports were assessed separately for eligibility and included. All abstracts were reviewed, and adequate articles that focused on rebiopsy were selected and included in this literature review (Figure 1).

\section{The pivotal role of Re-biopsy during Targeted Therapy}

Targeted therapy has emerged as an important means of disease management for patients with non-small-cell lung cancer (NSCLC). Understanding the molecular features of tumor tissues have provided a better method to eradicate cancer cells with less toxic effects compared to cytotoxic chemotherapy. Targeted therapy has significantly improved the field of precision oncology especially in the 


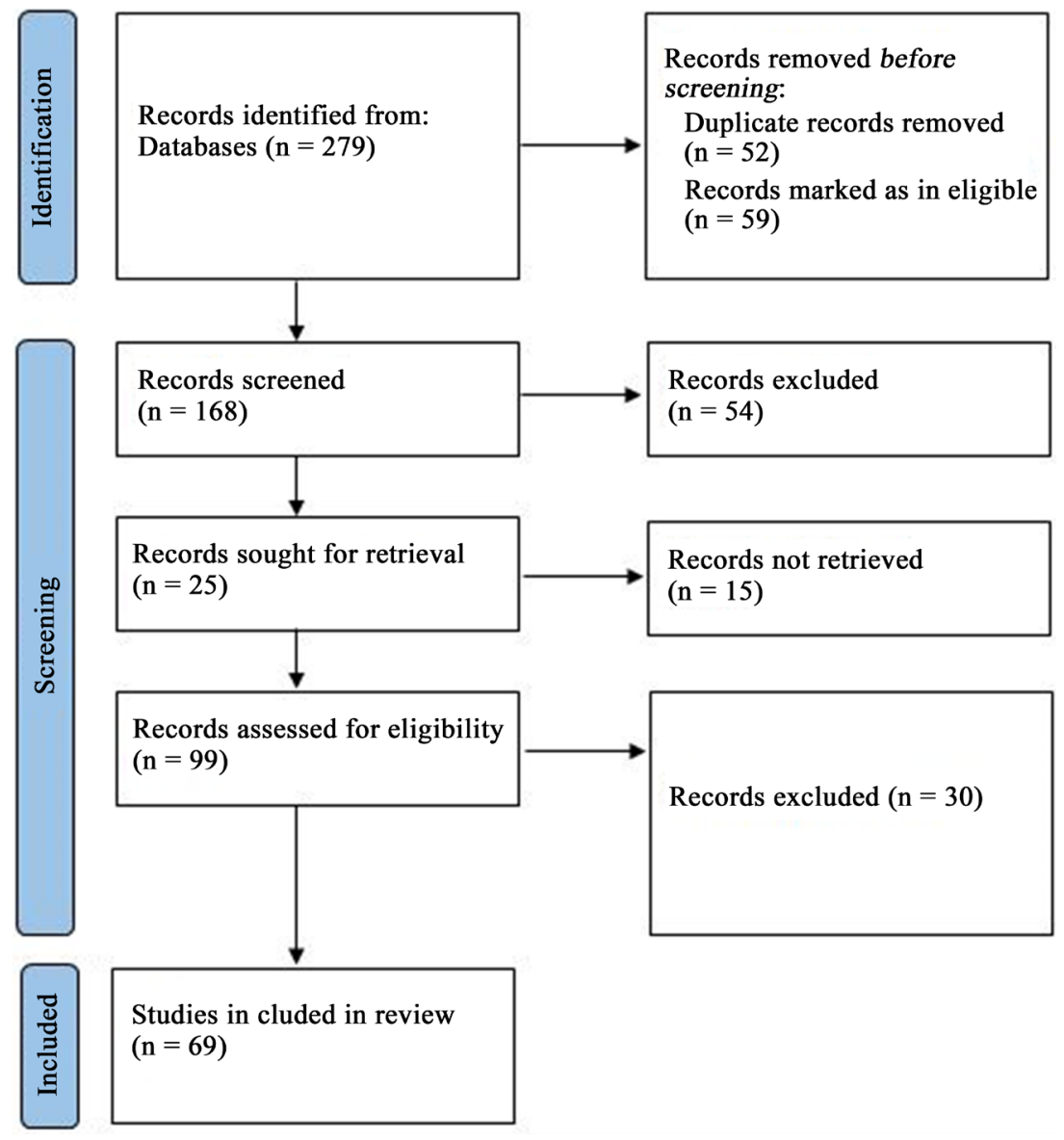

Figure 1. Identification and screening of literatures.

management of lung cancer. Identifying targetable genomic targets has become a gold standard approach since a favorable outcome was observed in lung cancer as well as in many other cancers. The molecular targets which are currently available in clinical practice are EGFR mutations, ALK rearrangements, ROS1, KRAS, and other signal transduction pathways including PI3K/AKT/mTOR, JAK/STAT, and MAPK/ERK, etc. Targeted drugs that are approved as a treatment modality in lung cancer to date are listed in Table 1.

Despite the significant benefit in the overall survival of lung cancer using targeted therapy, progression of the disease/recurrence is a common event even after a short span of targeted therapy. The reason behind it was well justified and proved with the identification of resistant clones post-targeted therapy (Table 2). The mechanisms of these therapeutic resistances are mandatory to develop a therapeutic approach against them. The emerging therapy approach which includes repurposing of the existing drug is also under investigation and some are documented in literature and guidelines (Table 3). The best example for such modality is the efficacy of ALK inhibitor Crizotinib in patients with MET amplification.

Another important targeted approach that revolutionized the treatment of lung cancer is the introduction of immunotherapy. They work by targeting the 
Table 1. Targeted drugs that are approved as a treatment modality in lung cancer.

\begin{tabular}{|c|c|c|c|}
\hline & Treatment & $\mathbf{N}$ & Median PFS (months) \\
\hline EGFR-TKI & & & \\
\hline NEJ2002 [7] [8] & \multirow{2}{*}{ Gefitinib vs. chemo } & 230 & 10.8 vs 5.4 \\
\hline WJTOG3405 [9] [10] & & 177 & 9.7 vs. 6.3 \\
\hline LUX-Lung 3 [11] & \multirow{2}{*}{ Afatinib vs. chemo } & 345 & 11.1 vs. 6.9 \\
\hline LUX-Lung 6 [12] & & 364 & 11.0 vs. 5.6 \\
\hline OPTIMAL [13] & \multirow{3}{*}{ Erlotinib vs. chemo } & 154 & 13.1 vs. 4.6 \\
\hline EURTAC [14] & & 173 & 9.7 vs. 5.2 \\
\hline ENSURE [15] & & 217 & 11.5 vs. 5.5 \\
\hline \multicolumn{4}{|l|}{ ALK-TKI } \\
\hline ALUR & Alectinib vs. chemo & 107 & 9.6 vs 1.4 \\
\hline ASCEND-5 & \multirow{2}{*}{ Ceritinib vs. chemo } & 231 & 5.4 vs 1.6 \\
\hline ASCEND-4 & & 376 & 16.6 vs 8.1 \\
\hline NCT00932893 & Crizotinib vs. chemo & 347 & 7.7 vs 3.0 \\
\hline NCT03052608 & Lorlatinib vs. Crizotinib & 296 & $\begin{array}{c}\quad 79 \% \text { vs } 39 \% \\
\text { (1 year event free survival) }\end{array}$ \\
\hline \multicolumn{4}{|l|}{ Immunotherapy } \\
\hline KEYNOTE-189 & Pembrolizumab + Chemo vs. Chemo & 616 & 8.8 vs 4.9 (Median PFS) \\
\hline IMPower110 & Atezolizumab vs Chemo & 205 & 20.2 vs 13.1 \\
\hline İMPower150 & $\mathrm{ABCP}$ vs $\mathrm{BCP}$ & 692 & 19.2 vs 14.7 \\
\hline CheckMate227 & $\begin{array}{c}\text { Nivolumab + Ipilimumab } \\
\text { vs Chemotherapy }\end{array}$ & 1739 & $\begin{array}{l}17.1 \text { vs } 14.9(\mathrm{PD}-\mathrm{L} 1 \geq 1 \%) \\
17.2 \text { vs } 12.2(\mathrm{PD}-\mathrm{L} 1<1 \%)\end{array}$ \\
\hline
\end{tabular}

Table 2. Resistance mechanisms to targeted therapy.

\begin{tabular}{cc}
\hline Acquired Resistance to EGFR-TKI & Acquired Resistance to ALK-TKI \\
\hline On target & On target \\
EGFR C797S & L1196M \\
EGFR ligand overexpression & G1202R \\
EGFR G724S, G797/797 & \\
EGFR L792, L718/G719 & \\
EGFR T790M & \\
Bypass tracks & Bypass tracks \\
MET amplification & MET amplification \\
RET fusion & EGFR pathway \\
FGFR3 fusion & SRC \\
BRAF mutation/fusion & IGF-1R \\
KRAS amplification & \\
HER2 amplification & \\
Histologic transformation & Transformation to small cell lung cancer
\end{tabular}


Table 3. Emerging drug molecules which can be used as targeted therapies.

\begin{tabular}{|c|c|}
\hline Targets/Mutation & Drug \\
\hline \multirow[t]{2}{*}{ NTRK Fusion } & Entrectenib \\
\hline & Larotrectinib \\
\hline BRAF V600E & Dabrafenib plus trametinib \\
\hline \multirow[t]{4}{*}{ EGFR exon 20 insertion } & Osimertinib \\
\hline & Poziotinib \\
\hline & Mobocertinib (TAK-788) \\
\hline & Compound 1A \\
\hline Hsp90 (EGFR exon 20 insertion) & Luminespib \\
\hline EGFR and MET & JNJ-6372 \\
\hline \multirow[t]{5}{*}{ METexon14 } & Crizotinib \\
\hline & Glesatinib \\
\hline & Tepotinib \\
\hline & Capmatinib \\
\hline & Telisotuzumab vedotin \\
\hline \multirow[t]{2}{*}{ KRAS G12C } & AMG 510 \\
\hline & MRTX849 \\
\hline \multirow[t]{4}{*}{ RET } & Cabozantinib \\
\hline & Vandetanib \\
\hline & LOXO-292 (Selpercatinib) \\
\hline & Pralsetinib \\
\hline \multirow[t]{5}{*}{ HER2 } & Trastuzumab and Trastuzumab emtansine (T-DM1) \\
\hline & Trastuzumab Deruxtecan (DS-8201a) \\
\hline & Dacomitinib \\
\hline & Afatinib \\
\hline & Pyrotinib \\
\hline FGFR & AZD4547 \\
\hline
\end{tabular}

immune checkpoints such as PDL1 and CTLA-4, hence called immune checkpoint inhibitors (ICI). Biomarkers used in the selection of immunotherapy for lung cancer include PD1/PDL1, tumor mutational burden (TMB), and microsatellite instability (MSI) however these are static biomarkers and a need for more dynamic biomarkers is felt for a more accurate prediction of response to ICI therapy [16]. On-therapy change in TMB $(\triangle T M B)$ is being explored as a dynamic biomarker that requires on-treatment biopsy at 4 weeks of treatment [17]. Multiple combination strategies are being explored for immunotherapy in NSCLC with driver mutations however results so far have been unsatisfactory. A low TMB along with an unfavorable tumor microenvironment (TME) is contributory to reduced efficacy to ICIs in EGFR mutated NSCLC. Both TMB and TME is 
still under investigation as a potential biomarker and estimating TME postprogression or recurrence requires a re-biopsy.

Therefore, the significance of re-biopsy in lung cancer patients is not only constrained to clinical practice but also adding a translational relevance by identifying new molecular targets and the possible resistance mechanisms [18]. However, re-biopsy in this class of advanced lung cancer patients is fraught with several challenges including access to the tumor, patient consent, and condition, safety, cost, etc., which are discussed below:

\section{Patient Perspective}

1) Cost: A study by Magee et al. demonstrated that the cost associated with a tissue-biopsy procedure is quite high making it unaffordable for patient population belonging to low-middle-income groups. Computed tomography (CT)-guided biopsy for biomarker testing and treatment of associated adverse events on an average cost $\$ 4130.09$ per patient. In patients experiencing complications, the cost is expected to rise to $\$ 18,567.23$ per patient. Although, navigational bronchoscopies had fewer associated complications, on average it costs $\$ 8283.62$ per procedure including treatment of complications. In patients experiencing complications, the cost is expected to rise to $\$ 22,720.76$ [19]. A recent observational study by Karve et al. also assessed the cost associated with biopsy procedures (both initial and post-progression) in patients with NSCLC (n 20,013) using the administrative claims data from commercially insured individuals in the U.S. (2006-2014). Bronchoscopy (initial 53\%; post-progression 71\%) and percutaneous needle biopsy (initial 42\%; post-progression 21\%) were performed in these NSCLC patients. The study found that the cost associated with biopsy was significantly higher in patients with complications as compared to those without complications (day of biopsy: $\$ 12,030$ vs. $\$ 6508$; within 7-days: $\$ 13,657$ vs. $\$ 7765$; p-value < 0.001) [20]. Thus, the high cost associated with tissue biopsies can limit their use by the patients.

2) Patient Condition: The patient with advanced NSCLC might not be able to undergo re-biopsy due to inaccessible tumor sites, rapid tumor progression, and poor performance status. Further, the small risk of complications such as pneumothorax and pulmonary hemorrhage associated with invasive lung biopsy procedures can pose an obstacle in conducted re-biopsy especially in patients with advanced disease [21].

3) Patients' Opinion: A study by Kawamura et al. investigated the limitations associated with re-biopsy in clinical practice. The study assessed 120 NSCLC patients with EGFR mutations who had a relapse of cancer after undergoing treatment with first-line TKIS. The study results showed that of the 45 patients who did not undergo re-biopsy, 6 were due to patient refusal [21]. Another study by Zanwar S et al. also reported patient unwillingness (44.1\%) to be the most common barrier in performing invasive re-biopsy. The other reasons of not performing a repeat biopsy as per this study were technical difficulty (29.4\%) poor performance status (17.6\%), and clinicians canceling the procedure due to 
un-stable patient and urgency (8.8\%) [22].

\section{4) Sampling issues}

Optimal sampling of lung cancer in a multidisciplinary setup is a combined effort of the medical and surgical oncologists, interventional radiologist, and the pathologist. Lung cancers may be heterogeneous with potential underrepresentation of molecular profile in a single biopsy specimen [23]. However, in practice, a good concordance has been seen in the genomic profile of the primary and the metastatic tumor [24] as well as between biopsies and resection specimens [25] [26] [27].

The samples obtained from advanced lung cancer are usually small formalin-fixed paraffin-embedded (FFPE) biopsies or cytology samples. On one hand, less invasive methods are preferred for tumor biopsy and on the other demand for tissue are increasing due to the increasing number of biomarker tests to be performed. This makes the judicious use of immunohistochemistry and other molecular tests on available tissue very important for lung biopsies and needs special attention in surgical pathology laboratories.

The DNA yield for molecular analysis using frozen samples is usually adequate [28]. High detection techniques require a minimum of 100 - 400 cells in the sample for successful mutation analysis [29] [30] [31].

\section{Institutional Limitations}

1) Physician's Expertise: In a recent study, the authors reported that the lower frequency of T790M mutations (33\%) detection could be linked to the lack of skill and experience to perform transbronchial biopsies and CT-guided needle biopsies [32].

2) Physician's Decision: A study by Chandrasekharan et al. reported physician reluctance to be the commonest reason for post-progression non-biopsy in NSCLC patients. Another study also reported technical difficulties and the physician's discretion to be the common barrier in performing invasive re-biopsy [33].

3) Storing of Tissue Blocks: Formalin-fixed paraffin-embedded (FFPE) blocks help preserve the morphology of the tissue for diagnosis. However, there are several limitations associated with using FFPEs. Firstly, the use of formalin can lead to cross-linking and chemical modifications of nucleotides in DNA thus impairing the quality of DNA. Secondly, longer storage duration leads to loss of nuclear, cytoplasmic, and membranous biomarkers in the cells.

\section{Laboratory Issues and Specimen Quality}

Turnaround Time for Biomarker Results: Magee et al. also assessed the time to treatment in patients undergoing tissue biopsy to obtain a sample for mutation testing. The study reported that tissue biopsy requires $1-2$ weeks to show biomarker results. In some patients, the sample obtained from tissue biopsy may not be enough to carry out molecular testing, thus requires re-biopsy to have more samples, thereby increasing the turnaround time for biomarker results, treatment decision making and treatment initiation.

The qualitative aspects of amplifiable DNA seem to be more important than 
specimen quantity [34] [35]. The pre-analytical histological or cytological factors can further compromise the quality of the specimens. Specimen quality for molecular testing is affected by pre-fixation time, type of fixation, and fixation time. It is known that major biochemical alterations occur in the tissues within 10 minutes of removal from the body.

The quality of a specimen is primarily influenced by pre-fixation time, the type of fixative, and fixation time. Significant biochemical alterations start to occur in tissues within 10 min after sampling or resection. Warm and cold ischemia time of specimens should be as little as possible. Documentation of ischemia time may be a good practice as it may affect subsequent analyses. The time from specimen acquisition and fixation should be less than 30 minutes. Fixation in neutral buffered formalin for 6 - 48 hours is preferred before further processing of the specimen. This process ensures a good DNA yield for genetic analysis and good antigen retrieval for immunohistochemistry. RNA is more labile and degrades rapidly, however current quantitative RT PCR techniques analyses RNA in FFPE tissue [36].

Better yield and quality of nucleic acids and proteins may be obtained using frozen specimens. The morphological fine details may be lost including nuclear features and thus may not be suitable for FISH analysis. The storage and handling of frozen specimens is also a challenge in laboratories requiring costly infrastructure and controlled conditions. Alcohol fixation also gives good results for molecular testing and is routinely used for cytology samples [36] [37] [38].

Frozen specimen provides a high quality of nucleic acids and proteins, and has been considered the most optimal sample for most molecular analysis. However, freezing does not preserve the morphological details of tissues well and the handling and storing of frozen samples require highly controlled conditions and costly infrastructure. Alcohol fixation generates a superior yield of nucleic acid compared with formalin, as it does not cause the chemical changes found in formalin-fixed specimens [39] [40] [41] [42] [43]. As most fixatives for cytology preparation are alcohol bases, cytology specimens are appropriate for DNA-based molecular assays [44]. However, they may alter the morphological details of the nucleus and are not recommended for tests that still depend on morphological evaluation, including fluorescent in situ hybridization (FISH) [45]. Heavy metal-based fixatives are not suitable for molecular testing. Decalcification of specimens from bony metastasis should be avoided and are usually not suitable for molecular analysis. Wherever necessary bony specimens should be decalcified with non-acid EDTA-containing solutions.

Heavy metal fixatives are not suitable for most molecular analyses because they cause DNA fragmentation, and the metals in the fixative compete with magnesium and interact with other enzymes that are critical in molecular assays [46]. Bone is a common site for the metastatic spread of lung cancer. Decalcification of the specimens obtained from bony metastases should be avoided and tissues treated with decalcifying solutions should not be used for molecular test- 
ing, as decalcifying solutions extensively degrade DNA [14]. This can be overcome by using non-acid EDTA-containing decalcification solutions [47] [48].

Tumor proportion relative to non-neoplastic tissue in the biopsy is the most important factor for optimal molecular testing results [49]. There is little consensus on the optimum tumor cellularity. The College of American Pathologists (CAP) Updated Molecular Testing Guideline for the Selection of Lung Cancer Patients for Treatment with Targeted Tyrosine Kinase Inhibitors, 2018, recommends that EGFR testing methods that detect mutations with at least 50\% tumor cellularity in the specimens should be used by the laboratories. The guideline further encourages laboratories to use (or make available at an external reference laboratory) more sensitive tests that are capable of detecting mutations in specimens with as little as $10 \%$ tumor cellularity.

Laboratories should use EGFR test methods that can detect mutations in specimens with at least 50\% cancer cell content, although laboratories are strongly encouraged to use (or have available at an external reference laboratory) more sensitive tests that can detect mutations in specimens with as little as $10 \%$ cancer cells. Multiple core biopsies reduce the likelihood of false-negative molecular analysis because of insufficient tumor cellularity, necrotic tissue, or crush artifact. Prompt feedback regarding core biopsy and cytology specimen adequacy and cellularity by the pathologist to the clinician is important for optimal patient management and continuous performance improvement [50].

\section{Role of Lung Cytology in Lung cancer Diagnosis}

The role of cytopathology is gaining importance with the increasing use of minimally invasive techniques like endobronchial ultrasound-guided fine-needle aspiration (EBUS FNA) which can frequently provide adequate material for diagnosis, immunohistochemistry, and mutation analysis [51]. In a study conducted by Rhian et al. for assessing the impact of cytological sampling on EGFR mutation testing in stage III-IV lung adenocarcinoma, it was found that cytological sampling was almost as effective as histological methods at acquiring adequate samples for analysis [52]. Current recommendations suggest that molecular analysis be conducted on highly sensitive polymerase chain reaction (PCR) based methods and/or FISH on lung cytology. In the advanced stage of lung cancer, the diagnosis and molecular analysis can be based on the analysis of cytology samples, especially FNA or bronchial brushings/washings obtained through minimally invasive procedures [53].

Even though formalin-fixed tissue samples provide good results with molecular investigations, formalin is also associated with some important limitations, including poor quality of nucleic acids due to structural damage and fragmentation in the process of DNA extraction [54] [55].

The cytology preparations are devoid of formalin fixation and thus provide an acceptable alternative source of quality DNA. Unstained direct smears, alcoholfixed Papanicolaou (PAP) stained, and air-dried Romanowsky stained (Diff-Quik/ Giemsa) smears can be used for molecular testing [56] [57]. 
DNA can be easily extracted from all the cytology preparations and is reasonably stable (6 mo. to 5 yrs.). The number of quality nuclei for FISH analysis is also adequate in both unstained and stained cytology specimens \$. A quality check for the cytology specimens is the "rapid on-site adequacy assessment" (ROSE), which helps in assessing the specimen adequacy for molecular testing during the procedure [51]. Cytologic samples however have limitations for validation, partly due to the lack of standardization between laboratories for specimen collection, processing, and staining methodologies [59].

\section{Liquid Biopsy as an Alternate to Tissue Biopsy}

Tissue biopsy is an invasive surgical technique. The invasive nature of tissue biopsy limits its use in patients with poor performance and inaccessible tumor sites. Further, inter and intratumor heterogeneity exists, thus complete genome alterations are not visible in a tissue biopsy sample [60] [61]. A tissue biopsy can be carried out with various methods including fine needle aspiration, bronchoscopy, autofluorescence bronchoscopy, endobronchial ultrasound, mediastinoscopy, thoracentesis, thoracoscopy, and electromagnetic navigation [62].

Although tissue biopsy is the standard choice for analyzing tumors, nowadays liquid biopsy is becoming a choice in patients with NSCLC [63]. It is well-known that tumor cells release cell-free nucleic acids which include circulating tumor DNA (ctDNA), cell-free RNA (cfRNA), and circulating tumor cells (CTCS) in the blood [64]. Pertinent biomarkers can be detected and monitored by liquid biopsy. However, somatic mosaicism in plasma remains a challenge for the accurate interpretation of liquid biopsy results. The somatic mutations in the plasma due to clonal hematopoiesis are a source of background biological noise in liquid biopsies [65].

Studies have also assessed the applicability of other biological samples including urine and saliva to detect EGFR mutations. These fluids are also found to contain DNA released from the tumor cells and can be used to predict cancer. Thus, sources of DNA i.e., blood, serum, plasma, saliva, and/or urine can be collected as an alternate to tissue specimen in liquid biopsy to analyze tumors for molecular alterations [66]. In NSCLC patients, EGFR mutation testing is required to examine the sensitivity to EGFR-TKIS to give personalized treatment. As NSCLC patients usually present with advanced-stage cancer, it poses obstacles in obtaining tissue samples for genotyping. Liquid biopsy with circulating tumor DNA is sometimes the method of choice for tumor genotyping in such advanced cases. In a study conducted by Haiyan et al., blood samples from 24 NSCLC patients were analyzed for EGFR mutation in CTCs and cfDNA and compared to matched tumor tissues showing a 50\% concordance. However, this study was limited with a time gap of up to seven years between the tissue biopsy and liquid biopsy [67].

Real-word data for liquid biopsy in clinical practice is accumulating. Real word data has shown a T790M detection rate by liquid biopsy of almost 25\%, using real-time PCR-based tests, while it up to 66\% using ddPCR [68] [69] [70]. A recent multi-center, real-life experience study in Italy for the practice of liquid 
biopsy in NSCLC also showed a good concordance [71].

Magee et al. compared the cost of blood-based mutation testing (Liquid biopsy) with tissue biopsy methods showed that blood-based test costs $\$ 836.45$ which is lesser than solid tissue biopsy methods (CT guided: $\$ 4130.09$ and navigational $\$ 8283.62$ ), leading to additional saving of $\$ 3293.64$ and $\$ 7447.17$, respectively. The study also reported that the turnaround time required for liquid biopsy is only 72 hours as compared to 1 - 2 weeks required for results of tissue biopsy. The Cobas EGFR Mutation Test v2, a liquid biopsy technique has been approved by the U.S. FDA to examine metastatic NSCLC patients for EGFR mutations including EGFR exon 21 L858R and T790M mutation to assess the targeted therapy with erlotinib and osimertinib, respectively [72] [73] [74].

In a study conducted by Lee SH et al., detection rates of EGFR-TKI oncogenic mutations (mEGFRs) in bronchial washing fluid showed a higher diagnostic efficacy compared with liquid biopsy in advanced NSCLC using droplet digital PCR (ddPCR) [75].

\section{Limitation of Liquid Biopsy}

The limitation of liquid biopsy is that it can lead to false-negative results, which can occur if the mutated DNA level in the DNA sample taken is low. A study by Kenneth et al. compared the different platforms for detecting EGFR mutations in plasma etDNA. The study used two digital platforms (Droplet Digital $^{\mathrm{TM}}$ PCR and BEAMing digital PCR [DPCR]) and two non-digital platforms (cobas ${ }^{\circledR}$ EGFR Mutation Test and therascreen ${ }^{\mathrm{TM}}$ EGFR amplification refractory mutation system assay) to analyze ctDNA. Concordance between the platforms was reported to be $>90 \%$. From the concordance sample (n 20), the four cases were detected as false negative by the cobas ${ }^{\circledR}$ EGFR Mutation Test but were detective positive by BEAMing. Seven were shown to be false negative by both plasma tests but were positive when matched with tumor tissue. This study stated that the reason for false-positive results could be a low allelic fraction of T790M or that might be too low to be detected by the Cobas EGFR Mutation Test. Tumor heterogeneity can be referred to explain the cause of the tissueplasma discordance, which is not due to technological limitations in the platforms used to analyze plasma. The study demonstrated high sensitivity (82\% - 87\%) and specificity (97\%) for EGFR-sensitizing mutations with the cobas ${ }^{\circledR}$ EGFR Mutation Test and BEAMing dPCR. Further, this study also demonstrated that T790M mutations can be detected more commonly in plasma samples of patients with metastatic disease as compared to locally advance diseases. Although liquid biopsy methods show false-negative results, studies have reported high concordance between liquid biopsy and tissue biopsy i.e. $>90 \%$ [76].

The finding of Clonal hematopoiesis $(\mathrm{CH})$ mutations from plasma cfDNA analysis should be cautiously analyzed for their potential pathological relevance. The $\mathrm{CH}$-mutations found in liquid biopsies are considered false positives however further studies need to be conducted to assess their clinical significance in healthy and cancer patients. Researchers are accelerated their approach to- 
wards liquid biopsy in recent years and most of them are concluded that liquid biopsy is a safe alternative and non-inferior to tissue biopsy. The advantages and disadvantages of liquid biopsy, as well as tissue re-biopsy, are illustrated in Table 4.

\section{Conclusions}

The discovery of oncogene-addicted non-small cell lung cancers and tyrosine kinase inhibitors, antibodies, and other small molecules that can target the specific driver pathways have revolutionized lung cancer treatment and have significantly improved the prognosis of affected patients. Currently, there are six target genes-EGFR (exon 19, L858R, T790M), ALK fusion, ROS1 fusion, BRAF V600E, MET, and NTRK fusion mutations. As has been described, multiple studies have shown the superiority of these higher generation targeted agents with respect to ORR, PFS (a few instances OS), and tolerability compared to chemotherapy or earlier generation targeted compounds.

Tissue biopsy has been a standard method to collect tumor samples and analyzing their mutational status. However, as most of the NSCLC patients are in their advanced and metastatic stages, it is difficult to conduct tissue biopsy due to inaccessible tumor sites, poor performance status, and tumor heterogeneity. Further, re-biopsy is challenged by cost, turnaround time, the clinical condition of the patient, physician's expertise, and individual's (patient/physician) opinion and treatment decision. Liquid biopsy in such cases is alternate and cost-effective

Table 4. Adavntages and disadvantages of tissue re-biopsy and liquid biopsy.

\begin{tabular}{|c|c|c|c|}
\hline \multicolumn{2}{|l|}{ Re-biopsy } & \multicolumn{2}{|l|}{ Liquid biopsy } \\
\hline Advantages & Disadvantages & Advantages & Disadvantages \\
\hline High sensitivity and specificity & $\begin{array}{l}\text { Invasive and limited use in patients } \\
\text { with poor performance status and } \\
\text { inaccessible tumor sites }\end{array}$ & $\begin{array}{l}\text { Less invasive and can be used in patients } \\
\text { with poor performance status and } \\
\text { inaccessible tumor sites }\end{array}$ & $\begin{array}{l}\text { Risk of false-positive results } \\
\text { are more }\end{array}$ \\
\hline $\begin{array}{l}\text { Histological transformations } \\
\text { and subtyping are possible }\end{array}$ & Turnaround time is more & $\begin{array}{l}\text { Turnaround time is less compared to tissue } \\
\text { biopsy }\end{array}$ & $\begin{array}{l}\text { Somatic mutations in the } \\
\text { plasma due to clonal } \\
\text { hematopoiesis hamper the } \\
\text { result }\end{array}$ \\
\hline $\begin{array}{l}\text { Confirmation on } \\
\text { metastases/relapse }\end{array}$ & $\begin{array}{l}\text { Complete genomic alterations are not } \\
\text { visible due to tumor heterogeneity }\end{array}$ & $\begin{array}{l}\text { Sources of DNA, such as blood, serum, } \\
\text { plasma, saliva, or urine can be analyzed for } \\
\text { molecular alterations }\end{array}$ & $\begin{array}{l}\text { Test sensitivity challenges still } \\
\text { exist due to the relatively low } \\
\text { level of circulating tumor cells } \\
\text { or DNA }\end{array}$ \\
\hline $\begin{array}{l}\text { Tumor microenvironment can } \\
\text { be checked }\end{array}$ & $\begin{array}{l}\text { Tissue biopsy from a metastatic site } \\
\text { may not explain the real nature of the } \\
\text { primary tumor }\end{array}$ & $\begin{array}{l}\text { Reported }>90 \% \text { concordance with tissue } \\
\text { re-biopsy }\end{array}$ & $\begin{array}{l}\text { Histologic transformations are } \\
\text { difficult to find }\end{array}$ \\
\hline $\begin{array}{l}\text { Immunohistochemistry is } \\
\text { cheaper than molecular } \\
\text { techniques in assessing } \\
\text { biomarkers such as PDL-1 }\end{array}$ & $\begin{array}{l}\text { Preservation methods such as } \\
\text { formalin fixation can result in } \\
\text { false-positive results in molecular } \\
\text { assays }\end{array}$ & $\begin{array}{l}\text { It can be easily repeated if needed and can } \\
\text { be used as often as necessary to monitor } \\
\text { the patient's progress } \\
\text { It can be used to estimate the risk for } \\
\text { metastatic relapse or metastatic } \\
\text { progression }\end{array}$ & $\begin{array}{l}\text { Very expensive as compared } \\
\text { to Immunohistochemistry }\end{array}$ \\
\hline
\end{tabular}


option when compared to tissue biopsy as it is a non-invasive procedure with less turnaround time and good sensitivity and specificity in detecting T790M mutations. Results for liquid biopsy are available within 72 hours, and in patients showing positive results, targeted therapy could be given to ensure improved PFS and quality of life. However, liquid biopsy can lead to false-negative results if the amount of mutated DNA is low in the sample taken. Thus patients with negative results go for a tissue biopsy.

\section{Conflicts of Interest}

The authors declare no conflicts of interest regarding the publication of this paper.

\section{References}

[1] Bray, F., Ferlay, J., Soerjomataram, I., Siegel, R.L., Torre, L.A. and Jemal, A. (2018) Global Cancer Statistics 2018: GLOBOCAN Estimates of Incidence and Mortality Worldwide for 36 Cancers in 185 Countries. CA: A Cancer Journal for Clinicians, 68, 394-424. https://doi.org/10.3322/caac.21492

[2] Lung Cancer-Non-Small Cell: Statistics. Cancer.Net. https://www.cancer.net/cancer-types/lung-cancer-non-small-cell/statistics

[3] Midha, A., Dearden, S. and McCormack, R. (2015) EGFR Mutation Incidence in Non-Small-Cell Lung Cancer of Adenocarcinoma Histology: A Systematic Review and Global Map by Ethnicity (mutMapII). American Journal of Cancer Research, 5 , 2892-2911.

[4] Kris, M.G., Natale, R.B., Herbst, R.S., Lynch, T.J., Prager, D., Belani, C.P., et al. (2003) Efficacy of Gefitinib, an Inhibitor of the Epidermal Growth Factor Receptor Tyrosine Kinase, in Symptomatic Patients with Non-Small Cell Lung Cancer: A Randomized Trial. Journal of the American Medical Association, 290, 2149-2158. https://doi.org/10.1001/jama.290.16.2149

[5] Dyer, O. (2003) FDA Announces Fast Track Approval of New Drug for Lung Cancer. BMJ, 326, 1004. https://doi.org/10.1136/bmj.326.7397.1004

[6] Lindeman, N.I., Cagle, P.T., Aisner, D.L., Arcila, M.E., Beasley, M.B., Bernicker, E.H., et al. (2018) Updated Molecular Testing Guideline for the Selection of Lung Cancer Patients for Treatment with Targeted Tyrosine Kinase Inhibitors Guideline from the College of American Pathologists, the International Association for the Study of Lung Cancer, and the Association for Molecular Pathology. Archives of Pathology and Laboratory Medicine, 142, 321-346. https://doi.org/10.5858/arpa.2017-0388-CP

[7] Maemondo, M., Inoue, A., Kobayashi, K., Sugawara, S., Oizumi, S., Isobe, H., et al. (2010) Gefitinib or Chemotherapy for Non-Small-Cell Lung Cancer with Mutated EGFR. The New England Journal of Medicine, 362, 2380-2388. https://doi.org/10.1056/NEJMoa0909530

[8] Inoue, A., et al. (2013) Updated Overall Survival Results from a Randomized Phase III Trial Comparing Gefitinib with Carboplatin-Paclitaxel for Chemo-Naïve Non-Small Cell Lung Cancer with Sensitive EGFR Gene Mutations (NEJ002). Annals of Oncology, 24, 54-59. https://doi.org/10.1093/annonc/mds214 https://www.annalsofoncology.org/article/S0923-7534(19)37027-9/abstract

[9] Mitsudomi, T., Morita, S., Yatabe, Y., Negoro, S., Okamoto, I., Seto, T., et al. (2012) 
Updated Overall Survival Results of WJTOG 3405, a Randomized Phase III Trial Comparing Gefitinib (G) with Cisplatin plus Docetaxel (CD) as the First-Line Treatment for Patients with Non-Small Cell Lung Cancer Harboring Mutations of the Epidermal Growth Factor Receptor (EGFR). Journal of Clinical Oncology, 30, 7521-7521. https://doi.org/10.1200/jco.2012.30.15_suppl.7521

[10] Mitsudomi, T., Morita, S., Yatabe, Y., Negoro, S., Okamoto, I., Tsurutani, J., et al. (2010) Gefitinib versus Cisplatin plus Docetaxel in Patients with Non-Small-Cell Lung Cancer Harbouring Mutations of the Epidermal Growth Factor Receptor (WJTOG3405): An Open Label, Randomised Phase 3 Trial. The Lancet Oncology, 11, 121-128. https://doi.org/10.1016/S1470-2045(09)70364-X

[11] Sequist, L.V., Yang, J.C.H., Yamamoto, N., O’Byrne, K., Hirsh, V., Mok, T., et al. (2013) Phase III Study of Afatinib or Cisplatin plus Pemetrexed in Patients with Metastatic Lung Adenocarcinoma with EGFR Mutations. Journal of Clinical Oncology, 31, 3327-3334. https://doi.org/10.1200/JCO.2012.44.2806

[12] Yang, J.C.H., Wu, Y.L., Schuler, M., Sebastian, M., Popat, S., Yamamoto, N., et al. (2015) Afatinib versus Cisplatin-Based Chemotherapy for EGFR Mutation-Positive Lung Adenocarcinoma (LUX-Lung 3 and LUX-Lung 6): Analysis of Overall Survival Data from Two Randomised, Phase 3 Trials. The Lancet Oncology, 16, 141-151. https://doi.org/10.1016/S1470-2045(14)71173-8

[13] Zhou, C., Wu, Y.L., Chen, G., Feng, J., Liu, X.Q., Wang, C., et al. (2011) Erlotinib versus Chemotherapy as First-Line Treatment for Patients with Advanced EGFR Mutation-Positive Non-Small-Cell Lung Cancer (OPTIMAL, CTONG-0802): A Multicentre, Open-Label, Randomised, Phase 3 Study. The Lancet Oncology, 12, 735-742. https://doi.org/10.1016/S1470-2045(11)70184-X

[14] Rosell, R., Carcereny, E., Gervais, R., Vergnenegre, A., Massuti, B., Felip, E., et al. (2012) Erlotinib versus Standard Chemotherapy as First-Line Treatment for European Patients with Advanced EGFR Mutation-Positive Non-Small-Cell Lung Cancer (EURTAC): A Multicentre, Open-Label, Randomised Phase 3 Trial. The Lancet Oncology, 13, 239-246. https://doi.org/10.1016/S1470-2045(11)70393-X

[15] Wu, Y., Zhou, C., Liam, C., Wu, G., Liu, X., Zhong, Z., et al. (2015) First-Line Erlotinib versus Gemcitabine/Cisplatin in Patients with Advanced EGFR Mutation-Positive Non-Small-Cell Lung Cancer: Analyses from the Phase III, Randomized, Open-Label, ENSURE Study. Annals of Oncology, 26, 1883-1889.

https://doi.org/10.1093/annonc/mdv270

[16] Joost Lesterhuis, W., Bosco, A., Millward, M.J., Small, M., Nowak, A.K. and Lake, R.A. (2017) Dynamic versus Static Biomarkers in Cancer Immune Checkpoint Blockade: Unravelling Complexity. Nature Reviews Drug Discovery, 16, 264-272. https://doi.org/10.1038/nrd.2016.233

[17] Riaz, N., Havel, J.J., Makarov, V., Desrichard, A., Urba, W.J., Sims, J.S., et al. (2017) Tumor and Microenvironment Evolution during Immunotherapy with Nivolumab. Cell, 171, 934-949. https://doi.org/10.1016/j.cell.2017.09.028

[18] Goldman, J.W., et al. (2020) Are Liquid Biopsies a Surrogate for Tissue EGFR Testing? Annals of Oncology, 29, i38-i46. https://doi.org/10.1093/annonc/mdx706 https://www.annalsofoncology.org/article/S0923-7534(19)31672-2/fulltext

[19] Magee, M., Arnaud, A. and Bowling, M. (2016) Costs and Outcomes Comparison of Tissue and Blood Based Biopsies for the Purpose of Biomarker Testing for Advanced Non-Small Cell Lung Cancer. https://doi.org/10.1016/j.jval.2016.03.1556 https://cdn2.hubspot.net/hubfs/5816323/downloads/Magee_et_al.pdf

[20] Karve, S., Turner, R., Chen, Y.-W., Rigas, J., Fernandes, A. and Kelly, R. (2017) 
P3.07-002 Complications and Costs of Diagnostic and Post-Progression Biopsies among Patients with Non-Small Cell Lung Cancer (NSCLC). Journal of Thoracic Oncology, 12, S1431. https://doi.org/10.1016/j.jtho.2016.11.2193

[21] Kawamura, T., Kenmotsu, H., Taira, T., Omori, S., Nakashima, K., Wakuda, K., et al. (2016) Rebiopsy for Patients with Non-Small-Cell Lung Cancer after Epidermal Growth Factor Receptor-Tyrosine Kinase Inhibitor Failure. Cancer Science, 107, 1001-1005. https://doi.org/10.1111/cas.12963

[22] Zanwar, S., Noronha, V., Joshi, A., Patil, V., Chougule, A., Kumar, R., et al. (2017) Repeat Biopsy in Epidermal Growth Factor Receptor Mutation-Positive Nonsmall Cell Lung Cancer: Feasibility, Limitations, and Clinical Utility in Indian Patients. Indian Journal of Cancer, 54, 280. https://doi.org/10.4103/ijc.IJC_215_17

[23] Jakobsen, J.N. and Sørensen, J.B. (2012) Intratumor Heterogeneity and Chemotherapy-Induced Changes in EGFR Status in Non-Small Cell Lung Cancer. Cancer Chemotherapy and Pharmacology, 69, 289-299.

https://doi.org/10.1007/s00280-011-1791-9

[24] Vignot, S., Frampton, G.M., Soria, J.C., Yelensky, R., Commo, F., Brambilla, C., et al. (2013) Next-Generation Sequencing Reveals High Concordance of Recurrent Somatic Alterations between Primary Tumor and Metastases from Patients with Non-Small-Cell Lung Cancer. Journal of Clinical Oncology, 31, 2167-2172. https://doi.org/10.1200/JCO.2012.47.7737

[25] Solomon, S.B., Zakowski, M.F., Pao, W., Thornton, R.H., Ladanyi, M., Kris, M.G., et al. (2010) Core Needle Lung Biopsy Specimens: Adequacy for EGFR and KRAS Mutational Analysis. American Journal of Roentgenology, 194, 266-269. https://doi.org/10.2214/AJR.09.2858

[26] Masago, K., Fujita, S., Mio, T., Ichikawa, M., Sakuma, K., Kim, Y.H., et al. (2008) Accuracy of Epidermal Growth Factor Receptor Gene Mutation Analysis by Direct Sequencing Method Based on Small Biopsy Specimens from Patients with Non-Small Cell Lung Cancer: Analysis of Results in 19 Patients. International Journal of Clinical Oncology, 13, 442-446. https://doi.org/10.1007/s10147-008-0772-4

[27] Han, H.S., Lim, S., An, J.Y., Lee, K.M., Choe, K.H., Lee, K.H., et al. (2012) Detection of EGFR Mutation Status in Lung Adenocarcinoma Specimens with Different Proportions of Tumor Cells Using Two Methods of Differential Sensitivity. Journal of Thoracic Oncology, 7, 355-364. https://doi.org/10.1097/JTO.0b013e31823c4c1b

[28] Williams, C., Pontén, F., Moberg, C., Söderkvist, P., Uhlén, M., Pontén, J., et al. (1999) A High Frequency of Sequence Alterations Is Due to Formalin Fixation of Archival Specimens. The American Journal of Pathology, 155, 1467-1471. https://doi.org/10.1016/S0002-9440(10)65461-2

[29] Pirker, R., Herth, F.J.F., Kerr, K.M., Filipits, M., Taron, M., Gandara, D., et al. (2010) Consensus for EGFR Mutation Testing in Non-Small Cell Lung Cancer: Results from a European Workshop. Journal of Thoracic Oncology, 5, 1706-1713. https://doi.org/10.1097/JTO.0b013e3181f1c8de

[30] Tam, A.L., Kim, E.S., Lee, J.J., Ensor, J.E., Hicks, M.E., Tang, X., et al. (2013) Feasibility of Image-Guided Transthoracic Core-Needle Biopsy in the BATTLE Lung Trial. Journal of Thoracic Oncology, 8, 436-442. https://doi.org/10.1097/JTO.0b013e318287c91e

[31] Savic, S., Tapia, C., Grilli, B., Rufle, A., Bihl, M.P., De Vito Barascud, A., et al. (2008) Comprehensive Epidermal Growth Factor Receptor Gene Analysis from Cytological Specimens of Non-Small-Cell Lung Cancers. British Journal of Cancer, 98, 154-160. https://doi.org/10.1038/sj.bjc.6604142 
[32] Shrimali, R., Bhargav, J., Arora, N., Midha, D., Parihar, M., Mishra, D., et al. (2017) 1: Tumours' Achilles' Heel, That Never Was-Experience of Re-Biopsy on Disease Progression on EGFR-TKIs in Lung Cancer (NSCLC) Patients from a Cancer Centre in Eastern India. Lung Cancer, 103, S1. https://doi.org/10.1016/S0169-5002(17)30051-X

[33] Chandrasekharan, A., et al. (2017) P3.02b-094 Rebiopsy Post Progression in EGFR Mutated Lung Cancer. Journal of Thoracic Oncology, 12, S1248-S1249. https://doi.org/10.1016/j.jtho.2016.11.1761

[34] Thunnissen, E., Kerr, K.M., Herth, F.J.F., Lantuejoul, S., Papotti, M., Rintoul, R.C., et al. (2012) The Challenge of NSCLC Diagnosis and Predictive Analysis on Small Samples. Practical Approach of a Working Group. Lung Cancer, 76, 1-18. https://doi.org/10.1016/j.lungcan.2011.10.017

[35] Dietel, M., Bubendorf, L., Dingemans, A.M.C., Dooms, C., Elmberger, G., García, R.C., et al. (2016) Diagnostic Procedures for Non-Small-Cell Lung Cancer (NSCLC): Recommendations of the European Expert Group. Thorax, 71, 177-184. https://doi.org/10.1136/thoraxjnl-2014-206677

[36] Srinivasan, M., Sedmak, D. and Jewell, S. (2002) Effect of Fixatives and Tissue Processing on the Content and Integrity of Nucleic Acids. American Journal of Pathology, 161, 1961-1971. https://doi.org/10.1016/S0002-9440(10)64472-0

[37] Babic, A., Loftin, I.R., Stanislaw, S., Wang, M., Miller, R., Warren, S.M., et al. (2010) The Impact of Pre-Analytical Processing on Staining Quality for H\&E, Dual Hapten, Dual Color in Situ Hybridization and Fluorescent in Situ Hybridization Assays. Methods, 52, 287-300. https://doi.org/10.1016/j.ymeth.2010.08.012

[38] Gillespie, J.W., Best, C.J.M., Bichsel, V.E., Cole, K.A., Greenhut, S.F., Hewitt, S.M., et al. (2002) Evaluation of Non-Formalin Tissue Fixation for Molecular Profiling Studies. The American Journal of Pathology, 160, 449-457.

https://doi.org/10.1016/S0002-9440(10)64864-X

[39] Doebele, R.C., Drilon, A., Paz-Ares, L., Siena, S., Shaw, A.T., Farago, A.F., et al. (2020) Entrectinib in Patients with Advanced or Metastatic NTRK Fusion-Positive Solid Tumours: Integrated Analysis of Three Phase 1-2 Trials. The Lancet Oncology, 21, 271-282. https://doi.org/10.1016/S1470-2045(19)30691-6

[40] Moding, E.J., Liu, Y., Nabet, B.Y., Chabon, J.J., Chaudhuri, A.A., Hui, A.B., et al. (2020) Circulating Tumor DNA Dynamics Predict Benefit from Consolidation Immunotherapy in Locally Advanced Non-Small-Cell Lung Cancer. Nature Cancer, 1, 176-183. https://doi.org/10.1038/s43018-019-0011-0

[41] Jiao, X.D., He, X., Qin, B.D., Liu, K., Wu, Y., Liu, J., et al. (2019) The Prognostic Value of Tumor Mutation Burden in EGFR-Mutant Advanced Lung Adenocarcinoma, an Analysis Based on cBioPortal Data Base. Journal of Thoracic Disease, 11, 4507-4515. https://doi.org/10.21037/jtd.2019.11.04

[42] Bai, Y., Chen, X., Hou, L., Qian, J., Jiang, T., Zhou, C., et al. (2018) PD-L1 Expression and Its Effect on Clinical Outcomes of EGFRmutant NSCLC Patients Treated with EGFR-TKIs. Cancer Biology and Medicine, 15, 434-442. https://doi.org/10.20892/j.issn.2095-3941.2018.0223

[43] Socinski, M.A., Jotte, R.M., Cappuzzo, F., Orlandi, F., Stroyakovskiy, D., Nogami, N., et al. (2018) Atezolizumab for First-Line Treatment of Metastatic Nonsquamous NSCLC. The New England Journal of Medicine, 378, 2288-2301. https://doi.org/10.1056/NEJMoa1716948

[44] Hofman, V. and Hofman, P. (2019) Resistances to EGFR Tyrosine Kinase Inhibitors in Lung Cancer-How to Routinely Track Them in a Molecular Pathology Labora- 
tory? Journal of Thoracic Disease, 11, S65-S70. https://doi.org/10.21037/jtd.2018.11.76

[45] Bepler, G., Williams, C., Schell, M.J., Chen, W., Zheng, Z., Simon, G., et al. (2013) Randomized International Phase III Trial of ERCC1 and RRM1 Expression-Based Chemotherapy versus Gemcitabine/Carboplatin in Advanced Non-Small-Cell Lung Cancer. Journal of Clinical Oncology, 31, 2404-2412. https://doi.org/10.1200/JCO.2012.46.9783

[46] Minari, R., Bordi, P., Del Re, M., Facchinetti, F., Mazzoni, F., Barbieri, F., et al. (2018) Primary Resistance to Osimertinib Due to SCLC Transformation: Issue of T790M Determination on Liquid Re-Biopsy. Lung Cancer, 115, 21-27. https://doi.org/10.1016/j.lungcan.2017.11.011

[47] Baloglu, G., Haholu, A., Kucukodaci, Z., Yilmaz, I., Yildirim, S. and Baloglu, H. (2008) The Effects of Tissue Fixation Alternatives on DNA Content: A Study on Normal Colon Tissue. Applied Immunohistochemistry \& Molecular Morphology, 16, 485-492. https://doi.org/10.1097/PAI.0b013e31815dffa6

[48] Wilson, I.G. (1997) Inhibition and Facilitation of Nucleic Acid Amplification. Applied and Environmental Microbiology, 63, 3741-3751. https://doi.org/10.1128/aem.63.10.3741-3751.1997

[49] Aisner, D.L., Deshpande, C., Baloch, Z., Watt, C.D., Litzky, L.A., Malhotra, B., et al. (2013) Evaluation of EGFR Mutation Status in Cytology Specimens: An Institutional Experience. Diagnostic Cytopathology, 41, 316-323. https://doi.org/10.1002/dc. 21851

[50] Lim, C., Sekhon, H.S., Cutz, J.C., Hwang, D.M., Kamel-Reid, S., Carter, R.F., et al. (2017) Improving Molecular Testing and Personalized Medicine in Non-Small-Cell Lung Cancer in Ontario. Current Oncology, 24, 103-110. https://doi.org/10.3747/co.24.3495

[51] Jain, D., Allen, T.C., Aisner, D.L., Beasley, M.B., Cagle, P.T., Capelozzi, V.L., et al. (2018) Rapid On-Site Evaluation of Endobronchial Ultrasound-Guided Transbronchial Needle Aspirations for the Diagnosis of Lung Cancer a Perspective from Members of the Pulmonary Pathology Society. Archives of Pathology \& Laboratory Medicine, 142, 253-262. https://doi.org/10.5858/arpa.2017-0114-SA

[52] Davies, R.S., Smith, C., Edwards, G., Butler, R., Parry, D. and Lester, J.F. (2017) Impact of Cytological Sampling on EGFR Mutation Testing in Stage III-IV Lung Adenocarcinoma. Lung Cancer International, 2017, Article ID: 9614938.

https://doi.org/10.1155/2017/9614938

[53] McLean, A., Barnes, D. and Troy, L. (2018) Diagnosing Lung Cancer: The Complexities of Obtaining a Tissue Diagnosis in the Era of Minimally Invasive and Personalised Medicine. Journal of Clinical Medicine, 7, 163.

https://doi.org/10.3390/jcm7070163

[54] da Cunha Santos, G. (2013) Standardizing Preanalytical Variables for Molecular Cytopathology. Cancer Cytopathology, 121, 341-343. https://doi.org/10.1002/cncy.21290

[55] Bhagwate, A.V., Liu, Y., Winham, S.J., McDonough, S.J., Stallings-Mann, M.L., Heinzen, E.P., et al. (2019) Bioinformatics and DNA-Extraction Strategies to Reliably Detect Genetic Variants from FFPE Breast Tissue Samples. BMC Genomics, 20, 689. https://doi.org/10.1186/s12864-019-6056-8

[56] Jain, D., Ramachandrappa, V.S., Singh, V., Malik, P.S., Madan, K., Faruq, M., et al. (2017) Use of Exfoliative Specimens and Fine-Needle Aspiration Smears for Mutation Testing in Lung Adenocarcinoma. Acta Cytologica, 61, 455-461. 
https://doi.org/10.1159/000479217

[57] Nalwa, A., Walia, R., Singh, V., Madan, K., Mathur, S., Iyer, V., et al. (2018) Comparison of Conventional Smear and Liquid-Based Cytology Preparation in Diagnosis of Lung Cancer by Bronchial Wash and Transbronchial Needle Aspiration. Journal of Cytology, 35, 94-98. https://doi.org/10.4103/JOC.JOC_248_16

[58] Lozano, M.D., Labiano, T., Zudaire, I., Subtil, J.C., Gurpide, A., Echeveste, J.I., et al. (2015) Variations in Molecular Profile in NSCLC Can Be Analyzed Using Cytological Samples: Development of EGFR Resistance Mutations and Coexistence of ALK-EML4 Translocation in an EGFR-Sensitive Patient. International Journal of Surgical Pathology, 23, 111-115. https://doi.org/10.1177/1066896914539551

[59] Lozano, M.D., Echeveste, J.I., Abengozar, M., Mejías, L.D., Idoate, M.A., Calvo, A., et al. (2018) Cytology Smears in the Era of Molecular Biomarkers in Non-Small Cell Lung Cancer Doing More with Less. Archives of Pathology and Laboratory Medicine, 142, 291-298. https://doi.org/10.5858/arpa.2017-0208-RA

[60] Lim, Z.F. and Ma, P.C. (2019) Emerging Insights of Tumor Heterogeneity and Drug Resistance Mechanisms in Lung Cancer Targeted Therapy. Journal of Hematology and Oncology, 12, 1-18. https://doi.org/10.1186/s13045-019-0818-2

[61] Sun, L., Li, Y.-Y., Ma, J.-T., Zhang, S.-L., Huang, L.-T. and Han, C.-B. (2019) The Influence of Tumor Heterogeneity on Sensitivity of EGFR-Mutant Lung Adenocarcinoma Cells to EGFR-TKIs. Translational Cancer Research, 8, 1834-1844. https://doi.org/10.21037/tcr.2019.09.01

[62] Corbetta, L., Arru, L.B., Mereu, C., Pasini, V. and Patelli, M. (2019) Review Competence in Interventional Pulmonology Competence and Training in Interventional Pulmonology. Panminerva Medica, 61, 203-234. https://doi.org/10.23736/S0031-0808.18.03562-0

[63] Spence, T., Perera, S., Weiss, J., Grenier, S., Ranich, L., Shepherd, F., et al. (2020) Clinical Implementation of Circulating Tumour DNA Testing for EGFR T790M for Detection of Treatment Resistance in Non-Small Cell Lung Cancer. Journal of Clinical Pathology, 74, 91-97. https://doi.org/10.1136/jclinpath-2020-206668

[64] Batth, I.S., Mitra, A., Manier, S., Ghobrial, I.M., Menter, D., Kopetz, S., et al. (2016) Circulating Tumor Markers: Harmonizing the Yin and Yang of CTCs and ctDNA for Precision Medicine. Annals of Oncology, 28, 468-477.

https://doi.org/10.1093/annonc/mdw619

[65] Chan, H.T., Chin, Y.M., Nakamura, Y. and Low, S.K. (2020) Clonal Hematopoiesis in Liquid Biopsy: From Biological Noise to Valuable Clinical Implications. Cancers, 12, 2277. https://doi.org/10.3390/cancers12082277

[66] Chang, S., Hur, J.Y., Choi, Y.-L., Lee, C.H. and Kim, W.S. (2020) Current Status and Future Perspectives of Liquid Biopsy in Non-Small Cell Lung Cancer. Journal of Pathology and Translational Medicine, 54, 204-212.

https://doi.org/10.4132/jptm.2020.02.27

[67] Liu, H.E., Vuppalapaty, M., Wilkerson, C., Renier, C., Chiu, M., Lemaire, C., et al. (2020) Detection of EGFR Mutations in cfDNA and CTCs, and Comparison to Tumor Tissue in Non-Small-Cell-Lung-Cancer (NSCLC) Patients. Frontiers in Oncology, 10, Article ID: 572895. https://doi.org/10.3389/fonc.2020.572895

[68] Minari, R., Mazzaschi, G., Bordi, P., Gnetti, L., Alberti, G., Altimari, A., et al. (2020) Detection of EGFR-Activating and T790M Mutations Using Liquid Biopsy in Patients with EGFR-Mutated Non-Small-Cell Lung Cancer Whose Disease Has Progressed during Treatment With First- and Second-Generation Tyrosine Kinase Inhibitors: A Multicenter Real-Life Retrospective Study. Clinical Lung Cancer, 21, 
e464-e473. https://doi.org/10.1016/j.cllc.2020.02.021

[69] Mondaca, S., Offin, M., Borsu, L., Myers, M., Josyula, S., Makhnin, A., et al. (2019) Lessons Learned from Routine, Targeted Assessment of Liquid Biopsies for EGFR T790M Resistance Mutation in Patients with EGFR Mutant Lung Cancers. Acta Oncologica, 58, 1634-1639. https://doi.org/10.1080/0284186X.2019.1645354

[70] Del Re, M., Petrini, I., Mazzoni, F., Valleggi, S., Gianfilippo, G., Pozzessere, D., et al. (2020) Incidence of T790M in Patients with NSCLC Progressed to Gefitinib, Erlotinib, and Afatinib: A Study on Circulating Cell-Free DNA. Clinical Lung Cancer, 21, 232-237. https://doi.org/10.1016/j.cllc.2019.10.003

[71] Cortiula, F., Pasello, G., Follador, A., Nardo, G., Polo, V., Scquizzato, E., et al. (2020) A Multi-Center, Real-Life Experience on Liquid Biopsy Practice for EGFR Testing in Non-Small Cell Lung Cancer (NSCLC) Patients. Diagnostics, 10, 765. https://doi.org/10.3390/diagnostics10100765

[72] Malapelle, U., Sirera, R., Jantus-Lewintre, E., Reclusa, P., Calabuig-Fariñas, S., Blasco, A., et al. (2017) Profile of the Roche cobas ${ }^{\circledR}$ EGFR Mutation Test v2 for Non-Small Cell Lung Cancer. Expert Review of Molecular Diagnostics, 17, 209-215. https://doi.org/10.1080/14737159.2017.1288568

[73] Premarket Approval (PMA). https://www.accessdata.fda.gov/scripts/cdrh/cfdocs/cfpma/pma.cfm?id=P150044

[74] Takahama, T., Azuma, K., Shimokawa, M., Takeda, M., Ishii, H., Kato, T., et al. (2020) Plasma Screening for the T790M Mutation of EGFR and Phase 2 Study of Osimertinib Efficacy in Plasma T790M-Positive Non-Small Cell Lung Cancer: West Japan Oncology Group 8815L/LPS Study. Cancer, 126, 1940-1948. https://doi.org/10.1002/cncr.32749

[75] Lee, S.H., Kim, E.Y., Kim, T. and Chang, Y.S. (2020) Compared to Plasma, Bronchial Washing Fluid Shows Higher Diagnostic Yields for Detecting EGFR-TKI Sensitizing Mutations by ddPCR in Lung Cancer. Respiratory Research, 21, 142. https://doi.org/10.1186/s12931-020-01408-X

[76] Thress, K.S., Brant, R., Carr, T.H., Dearden, S., Jenkins, S., Brown, H., et al. (2015) EGFR Mutation Detection in ctDNA from NSCLC Patient Plasma: A CrossPlatform Comparison of Leading Technologies to Support the Clinical Development of AZD9291. Lung Cancer, 90, 509-515. https://doi.org/10.1016/j.lungcan.2015.10.004 